Annals of International Medical and Dental Research

E-ISSN: 2395-2822 | P-ISSN: 2395-2814

Vol-8, Issue-2 | March-April 2022

DOI: 10.53339/aimdr.2022.8.2.2

Page no- 05-10 | Section- Research Article (Biochemistry)

\title{
Evaluation of Microalbuminuria in Patients with Urinary Tract Infection
}

\author{
Mohid Raza ${ }^{1}$, Maninder Kaur ${ }^{2}$, Harjinder Singh ${ }^{3}$, Ravinder Khaira ${ }^{4 *}$
}

\begin{abstract}
1Junior Resident, Department of Biochemistry, Government Medical College \& Rajindra Hospital Patiala, Punjab, India.

Email: mohid1985khan@gmail.com

Orcid ID: 0000-0001-8963-4381

2Professor, Department of Biochemistry, Government Medical College \& Rajindra Hospital Patiala, Punjab, India.

Email: mkaur68@yahoo.com

Orcid ID: 0000-0002-8709-7575

3Professor, Department of Urology, Government Medical College \& Rajindra Hospital Patiala, Punjab, India.

Email: dr.hsingh.uro@gmail.com

Orcid ID: 0000-0002-2745-4008

4Associate Professor, Department of Community Medicine, Government Medical College \& Rajindra Hospital Patiala, Punjab, India.

Email: axelkhaira31@gmail.com

Orcid ID: 0000-0001-7982-8895
\end{abstract}

*Corresponding author

Received: 22 October 2021

Revised: 03 December 2021

Accepted: 17 December 2021

Published: 18 February 2022

\begin{abstract}
Background: Urinary tract infection is a collective term for infections that involve any part of the urinary tract. It is one of the most common infections in local primary care. There are wide range of factors identified that can increase susceptibility to UTI, like sexual intercourse, congenital abnormalities, urinary obstruction, prior history of UTI, diabetes, urogenital surgery, estrogen deficiency. Diabetes mellitus has been a significant risk factor for complicated UTI. Presence of microalbumin in urine in patients of urinary tract infection may be a predictor of intrinsic renal pathology and its presence is a predictor of ongoing progressive damage to kidneys. Microalbuminuria is also associated with cardiovascular events and diabetic nephropathy. Early diagnosis of microalbuminuria will decrease the incidence of end stage renal disease and cardiovascular events. The present study was thus conducted to evaluate prevalence of microalbuminuria in patients diagnosed with urinary tract infections. Material \& Methods: The present hospital based case control study was conducted on 60 patients visiting the outpatient clinic (OPD) of Department of Urology, Government Medical College and Rajindra Hospital, Patiala and diagnosed with UTI and the control group consisted of 20 age and gender matched individuals. Estimation of urine microalbumin was done by Enyme linked immunoassay(ELISA) kit method in Department of Biochemistry, GMC Patiala. Results: Out of 60 cases of UTI included in the present study, prevalence of microalbuminuria was observed in $43.3 \%$ among cases of UTI . A total of $85 \%$ of the cases with positive urine culture had microalbuminuria ( $p<0.01$ ). Conclusions: Microalbuminuria and ACR can be recommended for predicting ESRD at an early stage of kidney disease.
\end{abstract}

Keywords:- Urinary tract infection, Albumin creatinine ratio, Microalbuminuria.

\section{INTRODUCTION}

Urinary tract infection (UTI) refers to the presence of microbial pathogens within the urinary tract. Diagnosis of urinary tract infection requires the presence of pus cells in the urine. Urinary tract infection is defined as the presence of 105 colony forming units (cfu)/mL in urine. Infection is uncomplicated when there is no underlying anatomical or functional abnormality. The underlying bacteriology of urinary tract infection mainly comprises of gram negative pathogens, most common of which is Escherichia coli. The pathogenic spectrum is more diverse and resilient in people with underlying systemic or local renal pathology indicating complicated infection. It is reported that UTI is affecting both genders but 
Annals of International Medical and Dental Research E-ISSN: 2395-2822 | P-ISSN: 2395-2814

Vol-8, Issue-2 | March-April 2022

DOI: 10.53339/aimdr.2022.8.2.2

Page no- 05-10 | Section- Research Article (Biochemistry)

women in the age of 15-44 are more prone to this infection. About $40 \%$ women and $12 \%$ of men suffers with urinary tract infection at least one time in their lifetime. Urine analysis usually reveals presence of protein in addition to leukocytes during urinary tract infection. Presence of this proteinuria is usually attributed to urinary tract infection, and overlooked.

It has also been postulated that underlying renal impairment predisposes to urinary tract infection suggesting if a person presents with UTI and proteinuria the possibility of intrinsic renal pathology cannot be excluded. Usual clinical practice in evaluation of proteinuria is to rule out urinary tract infection by midstream urine culture first before further investigations; if culture positive then infection is treated before proceeding ahead in workup of proteinuria. $[1,2]$

The present study is thus conducted to evaluate prevalence of microalbuminuria in patients diagnosed with urinary tract infections. Microalbuminuria is a subclinical rise in the urine albumin excretion. Microalbuminuria is defined as "urinary albumin excretion in the range of 30-299 mg/day in a 24 hour collection or $30-299 \mathrm{mg} / \mathrm{g}$ creatinine in a spot collection (preferred method).[]]

Urinary albumin to creatinine ratio (UACR) in a random spot urine is a easiest method for screening albuminuria. Normal UACR is generally defined as $<30 \mathrm{mg} / \mathrm{g}$, used for kidney damage screening in patients with diabetes. [4]

Microalbuminuria has been found to be an important prognostic indicator in meningitis, malignancies and hypertension. It has been found to be very useful in the monitoring of patients with renal scarring, unilateral nephrectomy and diabetes mellitus. Risk factors for microalbuminuria include diabetes, hypertension, obesity, smoking, hyperlipidemia, high salt diet, oral contraceptives and hormone replacement therapy.

\section{Aims and Objectives}

1. To evaluate Microalbuminuria in patients diagnosed with Urinary Tract Infections.

2. To calculate ACR (Albumin- Creatinine Ratio) in urinary tract infection patients.

\section{MATERIAL AND METHODS}

The present hospital- based case -control study was conducted over a period of two years on 80 individuals. Clinically confirmed cases of urinary tract infection in the age group 18-50 years were included in the study. The study sample included 60 individuals (with urinary tract infection) and the control group consisted of 20 age and gender matched individuals. This study has been approved by the Institutional Ethical Committee of the Government Medical College, Patiala.

\section{Inclusion Criteria}

1. Patients diagnosed with microbiological and radiological investigations for UTI

2. Patients with symptoms like increased frequency, burning and painful micturition and diagnosed with UTI.

3. Patients in the age group of 18 to 50 years.

4. Patients who have given their consent to be part of study. 
Annals of International Medical and Dental Research

E-ISSN: 2395-2822 | P-ISSN: 2395-2814

Vol-8, Issue-2 | March-April 2022

DOI: 10.53339/aimdr.2022.8.2.2

Page no- 05-10 | Section- Research Article (Biochemistry)

\section{Exclusion Criteria}

1. Patients with overt proteinuria, hematuria, congestive cardiac failure, renal failure, diabetes mellitus, obstructive uropathy and nephrolithiasis and pregnant females.

2. Macroalbuminuria (Urine Albumin Excretion $\quad>200 \mu \mathrm{g} / \mathrm{min} \quad$ OR $>300 \mathrm{mg} / 24$ hours).

3. Patients with contaminated urine samples.

4. Patients who have refused to be part of study.

\section{Methodology}

Patients fulfilling the inclusion criteria were involved in the study.

Purpose of the study was explained and informed consent was taken from patients and family in their vernacular language. In all the cases and controls the following laboratory evaluations were done.

\section{Laboratory Evaluation}

A) Routine Investigations

1. CBC (Hb,TLC,DLC,Platelet counts)

2. Blood urea

3. Serum Creatinie

4. Urinary Creatinine

5. RBS

6. Complete Lipid profile.

7. Urine complete examination.

B) Special Investigations

1. Urine Albumin Excretion $(\mu \mathrm{g} / \mathrm{ml})$ for Microalbuminuria.

2. Estimation of urinary creatinine. (Jaffe's method).[5]
Estimation of urine microalbumin level by Enzyme linked immunoassay (ELISA) (kit method). [6]

\section{Statistical Analysis}

The t-test was used for analysing quantitative data, or non-parametric data was analyzed by Mann Whitney test and categorical data was analyzed by using chi-square test. The significance threshold of $p$-value was set at $<0.05$. All analysis was carried out by using SPSS software version 21.25.

\section{RESULTS}

As shown in [Table 1] mean age of cases of UTI was $35.05 \pm 8.17$ years and mean age of control group was $34.20 \pm 9.58$ years. Age of both cases and controls was compared and was found non significant $(\mathrm{p}=0.701)$.

As shown in [Table 2], Cases of UTI included $66.7 \%$ females and $33.3 \%$ males. Both cases and controls were compared with respect to gender and was found non significant $(p=0.89)$.

As shown in [Table 3]

- A comparison of Microalbuminuria in study group and control group was done, The Mean \pm SD of Microalbuminuria was $41.33 \pm$ $35.54(\mu \mathrm{g} / \mathrm{dl})$ and $8.61 \pm 5.82(\mu \mathrm{g} / \mathrm{dl})$ in cases and controls respectively and was found significant $(\mathrm{p}=<0.01)$.

- A comparison of albumin creatinine ratio (ACR) in cases and controls was done, The Mean \pm SD of ACR was $40.79 \pm 34.78(\mathrm{mg} / \mathrm{g})$ and $6.91 \pm 6.17(\mathrm{mg} / \mathrm{g})$ in cases and control group respectively and was found significant $(p=<0.01)$. Normal ACR is $<30 \mathrm{mg} / \mathrm{g}$. 
Annals of International Medical and Dental Research E-ISSN: 2395-2822 | P-ISSN: 2395-2814

Vol-8, Issue-2 | March-April 2022

DOI: 10.53339/aimdr.2022.8.2.2

Page no- 05-10 | Section- Research Article (Biochemistry)

- A comparison of urinary creatinine in cases and controls was done, the Mean \pm SD of urinary creatinine was $120.37 \pm 57.77(\mathrm{mg} / \mathrm{dl})$ and $151.59 \pm 50.59(\mathrm{mg} / \mathrm{dl})$ in cases and control group respectively and was found significant as $p=<0.05(p=0.034)$. Normal urinary creatinine range is $20-320 \mathrm{mg} / \mathrm{dl}$ in men and 20-275mg/dl in women.
As shown in [Table 4], Out of total 26 microalbuminuric patients, 17 were urine culture-positive (85\%) and 9 were urine culturenegative $(22.5 \%)$. This comparison showed a significant association between urine culture and microalbuminuria ( $p$ value $<0.01$ )

Table 1: Mean age comparison among case and controls.

\begin{tabular}{|l|l|l|l|l|l|}
\hline Variables & Group & N & Mean & SD & p- value \\
\hline \multirow{2}{*}{ Age } & Controls & 20 & 34.20 & 9.58 & 0.701 \\
\cline { 2 - 5 } & Cases & 60 & 35.05 & 8.17 & \\
\hline
\end{tabular}

Table 2: Gender distribution among cases and controls

\begin{tabular}{|l|l|l|l|}
\hline \multirow{2}{*}{ Gender } & Group & Cases & Total \\
\cline { 2 - 4 } & Controls & 40 & \\
\hline \multirow{2}{*}{ Female } & 13 & $66.7 \%$ & 53 \\
\cline { 2 - 4 } & $65.0 \%$ & 20 & $66.3 \%$ \\
\hline \multirow{2}{*}{ Total } & 7 & $33.3 \%$ & 27 \\
\cline { 2 - 4 } & $35.0 \%$ & 60 & $33.8 \%$ \\
\hline \multirow{2}{*}{ p- value -0.89} & 20 & $100.0 \%$ & $100.0 \%$ \\
\cline { 2 - 4 } & $100.0 \%$ & \multicolumn{2}{l}{} \\
\hline
\end{tabular}

Table 3: Comparison of Microalbuminuria, ACR, and Urinary Creatinine among Study Group and control Group.

\begin{tabular}{|c|c|c|c|c|c|c|}
\hline S. No & Investigations & Group & $\mathbf{n}$ & Mean & SD & p-value \\
\hline \multirow[t]{2}{*}{1.} & \multirow{2}{*}{$\begin{array}{l}\text { Microalbuminuria (ELISA- } \\
20 \text { to } 200 \mu \mathrm{g} / \mathrm{dl} \text { ) }\end{array}$} & Controls & 20 & 8.61 & 5.82 & \multirow[t]{2}{*}{$<0.01$} \\
\hline & & Cases & 60 & 41.33 & 35.54 & \\
\hline \multirow[t]{2}{*}{2.} & \multirow{2}{*}{$\begin{array}{l}\mathrm{ACR}(30-300 \mathrm{mg} / \mathrm{g}) \\
\mathrm{ACR}=\mathrm{mg} / 1 \\
\quad \mathrm{gm} / 1\end{array}$} & Controls & 20 & 6.91 & 6.17 & \multirow[t]{2}{*}{$<0.01$} \\
\hline & & Cases & 60 & 40.79 & 34.78 & \\
\hline \multirow[t]{2}{*}{3.} & \multirow[t]{2}{*}{ Urine Creatinine(Jaffe's) } & Controls & 20 & 151.59 & 50.59 & \multirow[t]{2}{*}{$<0.05$} \\
\hline & & Cases & 60 & 120.37 & 57.77 & \\
\hline
\end{tabular}


Annals of International Medical and Dental Research

E-ISSN: 2395-2822 | P-ISSN: 2395-2814

Vol-8, Issue-2 | March-April 2022

DOI: 10.53339/aimdr.2022.8.2.2

Page no- 05-10 | Section- Research Article (Biochemistry)

Table 4: Association between Culture Positive UTI Patients and Microalbuminuria in the Study group $(\mathrm{n}=60)$

\begin{tabular}{|l|l|l|l|}
\hline $\begin{array}{l}\text { Urine Culture in UTI } \\
\text { Patients }\end{array}$ & Microalbuminuria & Normal & Total \\
\hline \multirow{2}{*}{$\begin{array}{l}\text { Culture } \\
\text { Negative }\end{array}$} & $\mathrm{n}=9$ & $\mathrm{n}=31$ & 40 \\
\cline { 2 - 4 } $\begin{array}{l}\text { Culture } \\
\text { Positive }\end{array}$ & $22.5 \%$ & $77.5 \%$ & $100.0 \%$ \\
\hline \multirow{2}{*}{ Total } & $\mathrm{n}=17$ & $\mathrm{n}=3$ & 20 \\
\cline { 2 - 4 } & $85.0 \%$ & $15.0 \%$ & $100.0 \%$ \\
\hline p- value $<0.01$ & 26 & 34 & 60 \\
\cline { 2 - 4 } & $43.3 \%$ & $56.7 \%$ & $100.0 \%$ \\
\hline
\end{tabular}

\section{DISCUSSION}

In present study mean age of cases of UTI was 34.2 years. There were $66.7 \%$ females and $33.3 \%$ males. Both cases and controls were comparable with respect to age, weight and mean systolic and diastolic pressure. In a similar study conducted by Zahra FT et al.[7] The mean age of cases was $54.81 \pm 20.25$ years with minimum and maximum age 16 and 93 years. There were 43 (25.3\%) cases with age 16-40 years, 58 (34.1\%) cases were $41-60$ years old and $69(40.6 \%)$ cases were $>60$ years of age. Another study Thattil SJ et al.[8] conducted to estimate the prevalence of UTI observed that the highest prevalence was observed in 26-35 years of age group.

Prevalence of UTI in females is due to close proximity of the urethral meatus to the anus, shorter urethra, sexual intercourse and incontinence . Muthulakshmi et al, $[9]$ study on UTI in females also showed that women in the reproductive age 14-44 years are the vulnerable group for UTI infection and 25-30\% women between 20-40 years of age are much affected. However, higher incidence was observed in middle age females and old age males by some studies which may be due to prostrate disease in males are responsible for the increase in the incidence of UTI above 45 years, because an enlarged prostate in men causes urethral obstruction and increased urinary retention due to prostate gland swelling.[10,11] Urinary infections associated with benign prostatic hyperplasia $(\mathrm{BPH})$ occur as patients are unable to completely empty their bladder and the stagnant urine acts as a growth medium for bacteria. Symptoms can be range from mild dysuria, frequency and urgency to severe systemic infections and frank hematuria causing acute retention. Our study also reported concordant results.

Out of 60 cases of UTI included in the present study, prevalence of microalbuminuria was observed in $41.7 \%$ among cases of UTI. Urinary tract infections are commonly said to be associated with positive results in reagent strip urinalysis for proteinuria, with some reviews suggesting between $63 \%$ and $83 \%$ of cases of culture-confirmed UTI having reagent-strip positive tests for protein. [12] Prevalence of microalbuminuria as reported by Zahra FT et al, [7] in their study was $47.1 \%$ while in the study by Efundem NT et al the prevalence was $26.5 \%$.[13] 
Annals of International Medical and Dental Research

E-ISSN: 2395-2822 | P-ISSN: 2395-2814

Vol-8, Issue-2 | March-April 2022

DOI: 10.53339/aimdr.2022.8.2.2

Page no- 05-10 | Section- Research Article (Biochemistry)

In our study a total of $85 \%$ of the cases with positive urine culture had microalbuminuria $(p<0.01)$. Another study by Bharara et al,14] established a significant association between culture positivity and proteinuria as well as pyuria $(\mathrm{p}<0.001)$.

Microalbuminuria is best recognized for the association with deterioration in renal function. Microalbuminuria may be present at an early stage of kidney disease, even when eGFR is normal. Recent recommendations suggest the use of albuminuria in addition to eGFR for the prediction of end stage renal disease (ESRD). Therefore routine checks for those at high risk for chronic disease should include albuminuria

\section{REFERENCES}

1. Fraser SD, Roderick PJ, McIntyre NJ, et al. Assessment of proteinuria in patients with chronic kidney disease stage 3: albuminuria and non-albumin proteinuria. PLoS One. 2014;9(5):e98261. doi:10.1371/journal.pone.0098261

2. Lamb EJ, MacKenzie F, Stevens PE. How should proteinuria be detected and measured? Ann Clin Biochem. 2009;46(Pt 3):205-17. doi: 10.1258/acb.2009.009007.

3. Toto RD. Microalbuminuria: definition, detection, and clinical significance. J Clin Hypertens (Greenwich). 2004;6(11 Suppl 3):2-7. doi:10.1111/j.1524-6175.2004.4064.x

4. American Diabetes Association. Standards of Medical Care in Diabetes-2019 Abridged for Primary Care Providers. Clin Diabetes. 2019;37(1):11-34. doi:10.2337/cd18-0105

5. Bowers LD. Kinetic serum creatinine assays I. The role of various factors in determining specificity. Clin Chem. 1980;26(5):551-4.

6. Ng LC, Teng LC, Ng ML, Sazali BS, Khalid BA. Microalbuminuria measurements by two in-house ELISA methods. Malays J Pathol. 2000;22(2):73-8.

7. Zahra FT, Safdar MF, Zubair HM. Analysis of Proteinuria in Urine Routine Examination During Urinary Tract Infection. Intern Med. 2018;8(286):2. http:/ / dx.doi.org/10.4172/2165-8048.1000287

8. Thattil SJ, Santhosh S. Prevalence of UTI in different age groups in a tertiary care hospital and their antibiogram. Int J Contemp Med Res. 2018;5(1):3-6. screening in order to prevent or delay possible progression to ESRD.

\section{CONCLUSIONS}

This study provides a positive association between culture- positive UTI and microalbuminuria, Therefore microalbuminuria can be regarded as a useful, relatively inexpensive, integrated marker to help identify patients at higher risk of ESRD (end stage renal disease), Microalbuminuria and ACR can be recommended for predicting ESRD at an early stage of kidney disease.

9. Muthulakshmi M, Gopalkrishnan S. Study on urinary tract infection among females of reproductive age group in a rural area of Kancheepruam district, Tamil Nadu. Int J Commu Med Public Health. 2017;4:3915-3921

10. Prakash D, Saxena RS. Distribution and antimicrobial susceptibility pattern of bacterial pathogens causing urinary tract infection in urban community of meerut city, India. ISRN Microbiol. 2013;2013:749629. doi: 10.1155/2013/749629.

11. Sood S, Gupta R. Antibiotic resistance pattern of community acquired uropathogens at a tertiary care hospital in jaipur, rajasthan. Indian J Community Med. 2012;37(1):39-44. doi:10.4103/0970-0218.94023

12. Foxman B, Barlow R, D'Arcy H, Gillespie B, Sobel JD. Urinary tract infection: self-reported incidence and associated costs. Ann Epidemiol. 2000;10(8):509-15. doi: 10.1016/s1047-2797(00)00072-7.

13. Efundem NT, Assob JCN, Feteh VF, Choukem SP. Prevalence and associations of microalbuminuria in proteinuria-negative patients with type 2 diabetes in two regional hospitals in Cameroon: a cross-sectional study. BMC Res Notes. 2017;10(1):477. doi: 10.1186/s13104-0172804-5.

14. Bharara T, Sharma A, Gur R, Duggal SD, PP JENA, et al. Predictive Role of Proteinuria in Urinary Tract Infection. J Clin Diagn Res. 2017;11(10):1-3.

Source of Support: Nil, Conflict of Interest: None declared 